\title{
Transformation of the principles of international private law in the digital age
}

\author{
Mariia Aleksandrina ${ }^{1, *}$ \\ ${ }^{1}$ Kulikova st. 36/2-21, Astrakhan, Russia, e-mail: aleks9999.72@inbox.ru
}

\begin{abstract}
The article focuses on the problem of transformation of the content of the principles of international private law in the context of digital development of the state, society and economy. The implementation and transformation of the principles of international private law in relation to the main types of cross-border public relations related to digital technologies are studied. It is established that in the context of the development of digital technologies, the most obvious transformation of the principles can be traced precisely in the process of concluding and executing smart contracts. A smart contract does not fit into the traditional criteria for determining either a civil contract or a foreign economic transaction. There is no uniform legal understanding of this phenomenon. It is noted that the content of the norms regulating modern cross-border private law relations related to the use of digital technologies should be built (along with other industry categories) on the basis of the principles of international private law, which, in turn, are transformed in connection with the needs of modern development of digital technologies and correspond to them.
\end{abstract}

\section{Introduction}

The rapid development of digital technologies has predetermined the formation of a new so-called digital information society, which requires appropriate changes in legal regulation. The structural and substantive reconstruction of the whole legal system involves not only the adaptation of existing legal norms to the features of public relations in a digital society (including an extended interpretation of their content), but also the further formation of digital law as an independent branch. Since the digital space and relations in a digital society often go beyond the borders of a single state, the problem of international legal regulation in this sphere is in the foreground. International private law is able to adapt earlier than other branches to the new conditions of digital development of the state, society, and economy, as it is characterized by more flexible methods of regulation, the lack in most cases of strict binding to national law, and the possibility of non-state regulation of relations in accordance with the principles of freedom of contract and autonomy of the will of the parties. In this regard, the research of the problem of transformation of the principles of international private law in the context of the development of the state, society and economy is of great theoretical and practical importance.

\section{Problem Statement}

In the course of this research, the following tasks are to be solved:

Determination of the system of principles of international private law in the context of the development of digital technologies;

Identification of changes in the content of the principles of international private law;

Study of the results of the transformation of the system of principles of international private law in accordance with the needs of practice;

Highlighting the features of the implementation of the principles of international private law in the process of regulating cross-border private law relations related to the use of digital technologies.

\section{Research Questions}

In the context of the development of digital technologies, the most obvious transformation of the principles can be traced in the process of concluding and executing smart contracts. A smart contract ("intellectual" contract, "clever" contract) is a self-executing contract based on the blockchain platform, concluded in electronic form, in which a mathematical code is used to enter all the terms of the contract into the blockchain. A smart contract does

*Corresponding author: aleks9999.72@inbox.ru 
not fit into the traditional criteria for determining either a civil contract or a foreign economic transaction. There is no uniform legal understanding of this phenomenon. The question of the mechanism for forming the terms of a smart contract remains is not clear. The place of conclusion, the personal law of the participants, the place of execution is difficult to determine. The problem of determining the applicable law to such contracts is related to the adaptation of the known conflict of laws principles exclusively to traditional civil law contracts. The problems of determining the place of conclusion of a smart contract, the place of execution, and the law of the country with which it is most closely connected are especially characterized for such contracts. The fundamental postulates, and, above all, the principles of international private law, do not find their expression in the traditional understanding. The problems of doctrinal formulation, legal consolidation of the principles of international private law, and the use of digital technologies in the field of international private law relations are paid attention both in domestic science [13] and in foreign studies [4-6].

\section{Purpose of the Study}

The purpose of the research is to study the problem of transformation of the content of the principles of international private law in the context of digital development of the state, society and economy.

\section{Research Methods}

The article uses the following methods: dialectical method, comparative legal method of research, method of system analysis.

\section{Findings}

The principles of international private law are the doctrinally formulated basic ideas that are formed in the course of the development of international private law relations and follow from the content of industry sources and their general meaning, which contribute to the achievement of the goals of legal regulation of international private law relations and in accordance with which the functions of international private law are performed.

The branch principles of international private law in various sources include: firstly, the principle of autonomy of the will of the parties to international private law relations (lex voluntatis)[7-8], the principle of the closest connection of legal relations [7,9] (at the same time, they are one of the main principles of conflict-of-laws regulation) and the principle of freedom of contract (the latter is concretizing in relation to the principle of autonomy of will), the territorial principle (the principle of applying the court's own law (lex fori) [10] the principle of conflict-of-laws regulation of private law relations with a foreign element (Tolochko, 2001), the principle of priority of the norms of international treaties over national legal norms [5] and the obligation of their execution [9] traditionally recognized in the scientific literature and enshrined in legal norms.

And also among the principles, for example, N. V. Oksyutchik highlights the principle of duality of sources of international private law, that is, the complex regulation of private law relations with a foreign element based on sources of international law and national law (in the literature, the principle of combining international and national regulation is highlighted) [4]; the principle of dispositivity (the possibility fixed in international legal sources for the parties to private-law relations with a foreign element to refuse to use them as regulators of these specific relations); the principle of combining state and non-state forms of regulation of international private law relations (that is, the "established order" that operates over a long period (lex mercatoria)) (for example, N. V. Oksyutchik formulates the principle of the application of non-state forms of regulation of legal relations) [4], however, the recognition of lex mercatoria as a legal regulator has not yet received mass distribution and is controversial [11]; fourthly, the principle of equality of the state as a participant in international private law relations and other subjects of international private law in accordance with the concept of functional immunity.

In addition, the literature highlights the principle of applying the norms of foreign law on the basis of conflict of laws rules or the agreement of the parties, taking into account the restrictions established in the imperative norms of national law and the public order clause [12]. Baryshev V. A. formulates two independent principles: the principle of mandatory application of foreign law, if it is required by conflict of laws rules or the parties have chosen it to regulate legal relations, and the principle of protecting the national law and order from the norms of foreign law that are incompatible with the established public legal consciousness and morality [9]. Akimova Yu. M. names two interrelated principles: the principle of application of foreign law and the principle of protection of domestic law and order [13].

In addition to the above-mentioned principles, the literature points to such principles of international private law as the principle of granting certain regimes and the principle of reciprocity [7]. In addition, it seems appropriate to add the principle of ensuring the execution of international private law obligations (ensuring the freedom of movement of goods and financial resources; compliance with guarantees to foreign investors) and the principle of conscientious execution of international private law obligations (conscientious competition and compliance with antimonopoly legislation), as well as the principle of personal data protection and information protection.

In the context of the development of digital technologies, the most obvious transformation of the principles can be traced in the process of concluding and executing smart contracts.

A smart contract ("intellectual" contract, "clever" contract) is a self - executing contract based on the blockchain platform, concluded in electronic form, in 
which a mathematical code is used to enter all the terms of the contract into the blockchain. Thus, the blockchain contains a special algorithm that allows you to automatically track the execution of participants (signatories) of their obligations.

A smart contract does not fit into the traditional criteria for determining either a civil contract or a foreign economic transaction. There is no uniform legal understanding of this phenomenon. For the first time, the term "smart contract" was legislated in the Decree of the President of the Republic of Belarus of December 21, 2017 No. 8 "On the development of the Digital Economy" [14]. The practical application of smart contracts remains outside the legal field due to their specifics, and it is impossible to distinguish the legal features of a computer program. Therefore, the original agreement of the parties containing the basic conditions, which has acquired the form of a digital code, is subject to regulation. Therefore, based on the analysis of foreign legislation and practice in the literature, it is proposed to consolidate the status of a smart contract as a way to formalize contractual obligations in the normative legal acts on contracts at the same time as making changes to the procedural legislation and normative legal acts on information technologies [15]. Federal Law of the Russian Federation No. 259-FZ of 31.07.2020 "On Digital Financial Assets, Digital Currency and on Amendments to Certain Legislative Acts of the Russian Federation" does not define a smart contract [16]. However, in the draft of this regulatory legal act, a smart contract was defined as "an contract in electronic form, the execution of rights and obligations under which is carried out by automatically performing digital transactions in a distributed register of digital transactions in a strictly defined sequence of such an contract and upon the occurrence of circumstances determined by it" [17].

Smart contracts do not originate from the parties, but as a result of the creation of a program based on digital technologies. Third parties with special names and special functions participate in their creation, control, execution and confirmation of transactions. The parties only conclude a smart contract, while simultaneously confirming their identity (and sometimes even this is not required). The question of the mechanism for forming the terms of a smart contract remains is not clear. The place of conclusion, the personal law of the participants, the place of execution is difficult to determine. The problem of determining the applicable law to such contracts is related to the adaptation of the known conflict of laws principles exclusively to traditional civil law contracts. The problems of determining the place of conclusion of a smart contract, the place of execution, and the law of the country with which it is most closely connected are especially characterized for such contracts. The distributional nature of the obligation contained in the smart contract implies the application of the personal law of each of the participants equally, as well as the participant of the blockchain [2]. Therefore, the traditional principles (the principle of conflict of laws regulation; the principle of autonomy of the will of the parties, based on the conflict of laws principle of determining the applicable law lex voluntatis; the principle of dispositivity, which implies the possibility of excluding the application of certain norms of international treaties and international customs; as well as the principle of combining state and non-state forms of regulation of international private law relations, which consists in the possibility of using business practices

in order to regulate contractual relations, that is, the so-called "routine order" that operates over a long period (lex mercatoria)) as the basis of legal regulation in relation to smart contracts, they are transformed into one general principle of automated determination of a more favorable right for a smart contract and autonomous supranational regulation. And in this form, these principles are preferably laid down in the algorithm for determining the applicable law when formulating the terms of a smart contract. At the same time, the so-called lex electronica system of self-regulation of relations on the Internet, based, among other things, on blockchain technology, is allowed to exist [1].

Since, first of all, just as in the case of concluding a traditional complex or unnamed contract, a conflict of laws problem may arise in connection with its qualification as an international commercial (crossborder) transaction [18], a similar problem may accompany smart contracts. In practice, the parties to smart contracts, in accordance with the principle of autonomy of will, often choose the most preferred legal systems that are most favorable to smart contracts. But if the nodes of the distribution registry network are located in the zones of different jurisdictions, there is a splitting of the treaty statute, which makes it much more difficult to choose the applicable law [2]. Building a strict algorithm for formulating the terms of a smart contract makes this process easier and faster, and also allows you to solve the conflict of laws problem. But to do this, the algorithm should be based on the principle of automated determination of a more favorable right for a smart contract (including in view of the possible use of smart contracts to ensure compliance with legal contracts). However, first "many technical and legal issues need to be resolved, which will require time and interdisciplinary discussion between lawyers and software developers" [16].

The quality of the contract is determined primarily by the use of clear and unambiguous terms, phraseological constructions that exclude the possibility of ambiguous interpretation. Arbitrary interpretation of certain regulatory requirements, on the basis of which the content of the contract is based, and its terms become impossible in the case of using smart contracts [18].

Qualification of smart contracts as accession contracts made under a suspensive condition [19], does not deprive them of fundamental differences from traditional civil law contracts. In this case, due to the lack of a single text expression of the contract, which does not allow us to reproduce the content of the transaction in the usual form, the formulation and fixing of the terms of the contract within the usual limits do not seem real. Smart contracts are more appropriate to use when concluding mass standard contracts. But if it is necessary to individually agree on the terms of the 
contract and, at the same time, the transfer of values expressed in bitcoins is not required, the creation of a smart contract is not substantiated [20]. Thus, the fundamental postulates, and, above all, the principle of freedom of contract, do not find their expression in the traditional understanding. This explains the need for a more specific definition of the boundaries of contractual regulation of relations arising on the basis of digital technologies, as opposed to traditional contractual relations [21].

The global nature and, in general, the unity of digital technologies used, including for the creation of smart contracts, can contribute to the formation of the principle of unified international legal regulation of relations in the sphere of digital space on the basis of the following principles of international private law: the principle of priority of the norms of international treaties over national legal norms and the obligation of their execution, as well as the principle of duality of sources of international private law, that is, the principle of comprehensive regulation of private law relations with a foreign element based on sources of international law and national law (in other words, the principle of combining international and national regulation).

The implementation within the framework of the digital space of the principle of equality of the state as a participant in international private law relations and other subjects of international private law in accordance with the concept of functional immunity does not cause any special problems. The program does not provide a different legal regime for users, and sometimes it depersonalizes them.

The principle of ensuring the execution of international private law obligations (especially in terms of ensuring the freedom of movement of goods and financial resources) and the principle of conscientious execution of international private law obligations in smart contracts receive the most guaranteed implementation due to the features of their execution. Smart contracts are self-executing contracts. If the conditions specified in the contract are met, an automatic transaction is made. The blockchain platform is built on the distribution principle. And even if there was a loss of data about the transaction for some technical reasons, the information does not completely disappear, and the payment can be confirmed by other participants. This is achieved by combining transactions into groups-blocks, from which a continuous chain is subsequently formed. At the same time, a distribution register is most acceptable for record-keeping of assets and their movement [23]. Provided that smart contracts are properly implemented, they can provide transaction security that surpasses traditional contract law. The costs of coordinating audit and ensuring compliance with such agreements are thus reduced [6] Therefore, the abovementioned principles are implemented, among other things, through the self-fulfillment of obligations characteristic of digital law, based on a distributed registry system.

Regarding the payment method, the traditional contract provides for its possible options: payment is made by transferring cash to the seller (contractor, etc.); by depositing funds in a notary's deposit; by bank transfer (by payment orders, by letter of credit, by collection, by cheques, etc.). In addition, the contract may specify the time when the payer executes the obligation to pay for goods (works, services): the time when funds are credited to the correspondent account of the recipient's bank, the time when funds are debited from the payer's current account, and the time when funds are credited to the recipient's current account. This is one of the differences from smart contracts, which can only work with assets located in the digital ecosystem. And the lack of legal regulation of the turnover of cryptocurrencies is the reason for limiting their turnover. For the same reason, the corresponding uniform judicial practice has not developed [23]. In fairness, it should be noted that the first steps in this direction are being taken at the national level. On January 1, 2021, Federal Law No. 259-FZ of 31.07.2020 "On Digital Financial Assets, Digital Currency and on Amendments to Certain Legislative Acts of the Russian Federation" [16] had been enacted. However, it does not contain the concept of a smart contract. And in this regard, the abovementioned principles of ensuring the execution of international private law obligations (especially in terms of ensuring the freedom of movement of goods and financial resources) and the conscientious execution of international private law obligations are expressed and implemented, including in the norms that fix the requirements for the activities of information system operators and operators of the exchange of digital financial assets [16].

Cryptocurrencies are used to make payments when executing the terms of smart contracts. But recently, the use of cryptocurrencies has been questioned, and bitcoin has been severely criticized due to the constant increase in the cost of maintaining the underlying blockchain system [24]. Other disadvantages of cryptocurrencies include: the lack of official exchange procedures, the impossibility of canceling transactions and returning funds in case of fraud, the vulnerability to hacking of cryptocurrency payment systems, and the lack of guarantees for the execution of transactions [25]. In addition, as practice has shown, there are no criteria on the basis of which it is possible to at least approximately calculate the possible exchange rate of cryptocurrencies. But, on the other hand, this payment method is currently more convenient and faster in relation to smart contracts. Its attractiveness is especially evident in the case of the supply chain implementation.

Payment systems based on blockchain technology continue to develop. The most well-known bank settlement system is SWIFT. However, recently it has shown vulnerability to hacker attacks. We can name the GPSG system, which is considered as a competitor to SWIFT, the new CLS Not platform, etc.[26]. In this regard, the implementation of international settlements on the basis of the principle of freedom and security of the movement of financial resources becomes relevant.

In the digital age, problems related to the protection of personal information and the identification of the subjects of relations arising through the use of the Internet also come to the foreground. At the international 
level, the principle of personal data protection is implemented in the provisions of the Convention for the Protection of Physical Persons in the Automated Processing of Personal Data of January 28, 1981. (as amended on 15 June 1999) [27], which enshrines that any person should be given the opportunity to know about the existence of an automated personal data file and the name, place of residence or location of the file controller, to obtain confirmation of whether his data is stored in an automated file, to seek, if necessary, correction or destruction of such data, to resort to legal remedies in cases of violations of rights in this sphere. In general, the Convention aims to protect physical persons from abuse in the collection and processing of personal data and to regulate the cross-border flow of personal data. Russia joined the Convention by signing its Protocol on October 10, 2018. And at present, the Convention on the Protection of Physical Persons in the Automated Processing of Personal Data of January 28, 1981. (as amended on June 15, 1999), known as "Convention 108", remains the only global international treaty in the field of personal data protection.

On the basis of the principle of personal data protection, the problem of identifying subjects should be solved: in which cases identification is possible and necessary; the right to use a pseudonym (network name); the right to oblivion and "digital death". The literature suggests two solutions to this problem: to recognize a virtual person who cannot be identified as an independent subject of private legal relations arising on the Internet; to recognize personal data as an object of civil law [28].

\section{Conclusion}

Modern needs determine the creation of a completely new system of legal norms regulating relations that are based on digital technologies. The content of such norms is built (along with other industry categories) on the basis of the principles of international private law, which, in turn, are transformed in connection with the needs of modern development of digital technologies and correspond to them. The system of principles of international private law, the implementation and transformation of individual principles in accordance with modern trends in the development of digital technologies and their application in various private law areas require special research.

\section{References}

1. N.V. Lukyanov, Legal Studies 11, 28-35 (2018)

2. M.V. Mazhorina, Lex Russica 7, 93-107 (2019)

3. N.V. Mamaeva, Science and education today 2 (25), 6-7 (2018)

4. N.V. Oksyutchik, Journal of International Law and International Relations 1-2 (84-85), 13-17 (2018)

5. O.N. Tolochko, Belarusian Journal of International Law and International Relations 2
(2001),

URL: https://elib.bsu.by/bitstream/123456789/29310/ 1/2001 2 JILIR tolochko_r.pdf (date of access: 16.03.21).

6. Sherman, Voshmgir. Token Econoimy: How the Web 3 reinvents the Internet (English) Taschenbuch $\quad-\quad 5, \quad$ (2020) URL: https://blockchainhub.net/blog/blog/token -economy-book-shermin-voshmgir/ (date of access: 16.03.21).

7. I.V. Getman-Pavlova, International private law: a short course of lectures (Moscow: Publishing house Yurayt, 2014)

8. D.P. Strigunova, Bulletin of the Moscow University of the Ministry of Internal Affairs of Russia 1, 47-51 (2017)

9. V.A. Baryshev, International private law. (Minsk: "Vysheyshaya shkola", 2019)

10. A.V. Asoskov, Fundamentals of Conflict of Laws (Moscow: Logos, 352, 2017)

11. A.N. Novikova, Social Sciences 12 (24), 59-63 (2013)

12. D.P. Strigunova, Modern law 4, 153-158 (2014)

13. Yu.M. Akimova, Actual Problems of Russian Law 5 (30), 600-606 (2013)

14. President of the Republic of Belarus Decree "On the Development of the Digital Economy" (21 December 2017 No 8). Minsk, Belarus. URL: https://www.economy.gov.by/uploads/fil es/sanacija-i-bankrotstvo/Dekret-

PrezidentaRespubliki-Belarus-ot-21-12-2017N-8-O-r.pdf (date of access: 16.03.21).

15. N.B. Krysenkova, International public and private law 5, 28-30 (2019)

16. State Duma of the Russian Federation Federal Law "On Digital Financial Assets, Digital Currency and on Amendments to Certain Legislative Acts Of the Russian Federation" (July 31, 2020 No. 259-FZ). Moscow, Russia. URL: http://www.consultant.ru/document/cons doc LAW 358753/ (date of access: 16.03.21).

17. State Duma of the Russian Federation Federal Law "On Digital Financial Assets, Digital Currency and on Amendments to Certain Legislative Acts Of the Russian Federation" (May 17, 2018). Moscow, Russia. URL: https://sozd.duma.gov.ru/bill/419059-7(date of access: 16.03.21).

18. M.V. Mazhorina, Journal of the Higher School of Economics 2, 143-159 (2016)

19. M.L., Davydova, \& M.Yu. Kozlova, Bulletin of the Nizhny Novgorod Academy of the Ministry of Internal Affairs of Russia 3 (47), 113-118 (2019)

20. M., Aleksandrina, \& M.Y. Kozlova, (2021) 'Smart Contracts' vs Legal Technology in Contract Practice. Lecture Notes in Networks and Systems 155, 1204-1212

21. A.V. Efimov, Journal of Russian law 7, 52-63 (2020) 
22. E.V. Voblenko, Accounting of digital transactions: dissertation for the degree of Candidate of Economic Sciences: (St. Petersburg State University of Economics, S.P., , 2020)

23. O.S., Grin, E.S Grin \& A.V. Soloviev, Lex Russica 8 (153), 51-62 (2019)

24. D.V. Lipnitsky, Industrial Economics 1, 82-100 (2019)

25. S. Yu. Pertseva, State Councillor 2 (26), 58-63 (2019)

26. V.E. Ponomarenko, Legal Science 5, 113-121 (2017)

27. Council of Europe Convention for the protection of physical persons in the automated processing of personal data (28 January 1981, 15 June 1999) Strasbourg, France. URL: http://www.consultant.ru/document/cons doc_LAW_121499/637cbbf46b43d8a53a38d13 19556d0beae26d7de/ (date of access: 16.03.21).

28. E.V. Talapina, Journal of Russian Law 2, 5-17 (2018) 